\title{
Design, Implementation and Testing of a Novel Prototype Orthotic Knee Joint with Two Degrees of Freedom in a Patient with Medial Knee Osteoarthritis
}

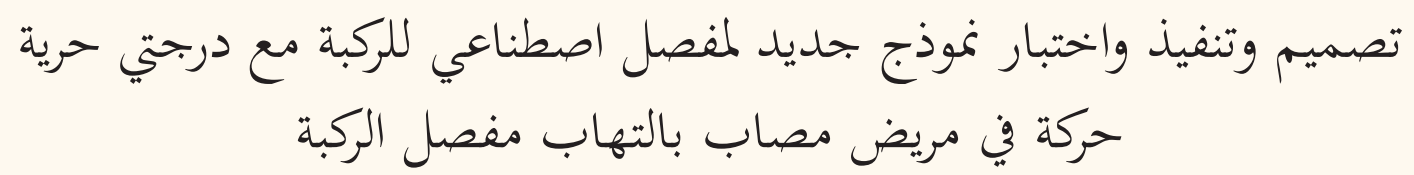

سيامك آقاجاني فشاركي، فرزام فرهمند، حسن سعيدي، إحسان عبدالهي

ABSTRACT: Knee braces are a conservative treatment option for patients with knee osteoarthritis (KOA). However, no commercially available orthotic knee joint currently reflects natural knee movements. A prototype orthotic knee joint with two degrees of freedom (DOF) in the sagittal and transverse planes was developed to more closely simulate the natural motion of the knee joint. The prototype was tested on a male subject with medial KOA during a sit-to-stand task. The efficacy of the transverse plane DOF was assessed by comparing the limb-orthosis interaction force when the transverse plane was locked to mimic a one-DOF setting versus when it was unlocked. Unlocking the transverse plane eliminated the 45-Newton shearing force produced with the one-DOF setting at wide angles of flexion. The two-DOF orthotic knee joint prototype demonstrated greater conformity to natural knee movements, allowing the wearer to better tolerate bracing-related difficulties.

Keywords: Knee Joint; Knee Osteoarthritis; Orthotic Devices; Braces; Rotation; Movement; Materials Testing.

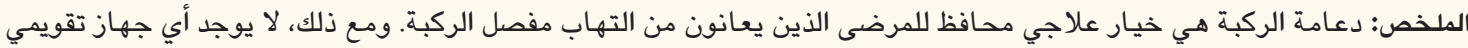

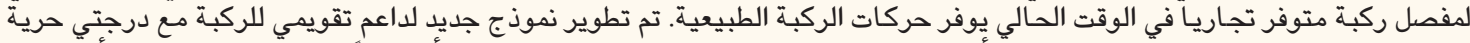

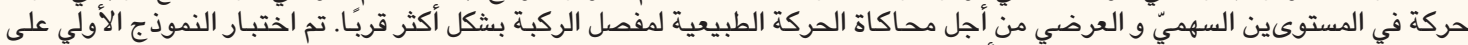

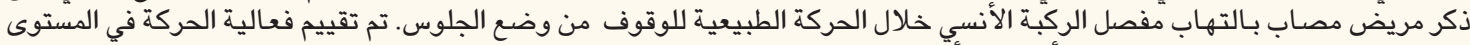

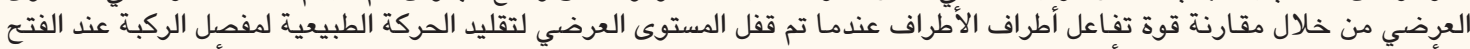

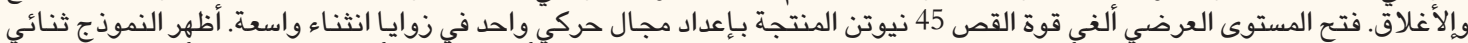

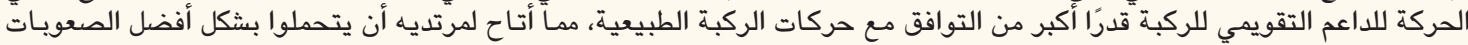
المتعلقة بالحركة.

الكلمات المفتاحية: مفصل الركبة؛ التهاب مفصل الركبة؛ أجهزة تقويم العظام؛ أجهزة داعمة؛ داعمدوران؛ حركة؛ اختبار المواد.

$\mathrm{K}$ BRACES ARE A CONSERVATIVE TREATment option for patients with medial knee positive effects of various types of knee braces, they limit the motion of the joint in all directions. ${ }^{4,5}$ This is partly due to the structural design of these orthotic devices, which generally follow simpler kinematic pathways than those of the natural anatomic knee joint. This mismatch can result in the pistoning of the brace components over the lower limb, constraining the wearer's normal range of motion with the subsequent distal movement and potentially leading to misalignment of the brace and uncomfortable pressure on the skin. ${ }^{6}$ Furthermore, axial misalignment causes unnecessary reaction forces at skin and joint attachment points, resulting in discomfort and even outright injury. ${ }^{7}$

Currently available orthotic knee joints, including both single-axis or polycentric devices, have one degree of freedom (DOF) in the sagittal plane and therefore can only mimic the range of flexion and extension of the anatomic knee, thus restricting the joint's natural movement. ${ }^{8,9}$ As such, the incorporation of an additional DOF in the transverse plane would allow the brace to more closely imitate the natural motion of the knee by allowing internal and external rotation.

To the best of the authors' knowledge, no commercially available orthotic knee joint with more than one DOF is currently available. ${ }^{8,9}$ As such, a prototype orth- 
otic knee joint was developed with two DOF in both the sagittal (i.e. flexion/extension) and transverse (i.e. internal/external rotation) planes. The prototype was tested to determine its efficacy in more closely simulating the natural motion of the knee joint by assessing the limb-orthosis interaction force when the transverse plane DOF was locked versus when it was unlocked.

\section{Methods}

The first step in developing the two-DOF orthotic knee joint prototype involved sketching potential designs in order to choose a realistic option for bracing the knee joint. Secondly, currently available polycentric knee joints were examined, modified and tested following the addition of a rotary component. A computer-aided design was then created digitally using SolidWorks ${ }^{\circledR}$, Version 5 (Dassault Systèmes, Paris, France) and CATIA ${ }^{\mathrm{TM}}$ software, Version 5 (Dassault Systèmes). This allowed for more detailed conceptual input and to assess whether the orthotic knee joint could be manufactured. The design and construction of the prototype was performed concurrently in the Djavad Mowafaghian Research Center of Intelligent Neuro-Rehabilitation Technologies and the Department of Orthotics \& Prosthetics of the Iran University of Medical Sciences, Tehran, Iran.

The final design of the prototype consisted of a polycentric hinge with a hyperextension stop to allow flexion/extension and a drawer joint above the polycentric hinge for transverse rotation [Figures $1 \mathrm{~A}$ and $\mathrm{B}$ ]. The transverse plane motion of the drawer joint could be locked by a screw and plate, hindering the joint's movement in the transverse plane and mimicking oneDOF products currently available in the market. ${ }^{8,9}$ When unscrewed and detached, the joint was released and the device returned to its original two-DOF configuration [Figure $1 \mathrm{C}$ ]. Overall, the range of motion of the prototype in the sagittal and transverse planes was 140 and 20 degrees, respectively [Table 1].

The drawer joint measured $60 \times 47 \times 15 \mathrm{~mm}$, weighed $300 \mathrm{~g}$ and was made from stainless steel. The aluminium sidebars $(20 \times 5 \mathrm{~mm})$ attached proximally to the drawer joint as femoral components and distally to the polycentric hinge as tibial components. The hinge was mediolaterally attached to a knee brace consisting of white copolymer polypropylene and 4-mm-thick anterior thigh and tibial shells lined with a 5-mmthick ethylene vinyl acetate (EVA) copolymer closed cell foam for comfort. Four 5-mm-wide nylon straps with hook and loop closures were attached around the outside of the device to allow the wearer to adjust the fit. Each strap had a protective pad made from a 5-mmthick EVA copolymerclosed cell foam positioned to protect the posterior leg skin [Figures 1D-F].

Subsequently, the testing phase was initiated to assess the performance of the prototype. A 45-year-old male subject with grade II medial KOA according to Kellgren and Lawrence classifications was recruited to perform a sit-to-stand task. ${ }^{10}$ Briefly, the subject was asked to rise from sitting in a chair and, after a short pause, sit down again without support at a self-selected speed. The chair had no arms and was adjusted to the subject's height to ensure that the thighs lay parallel

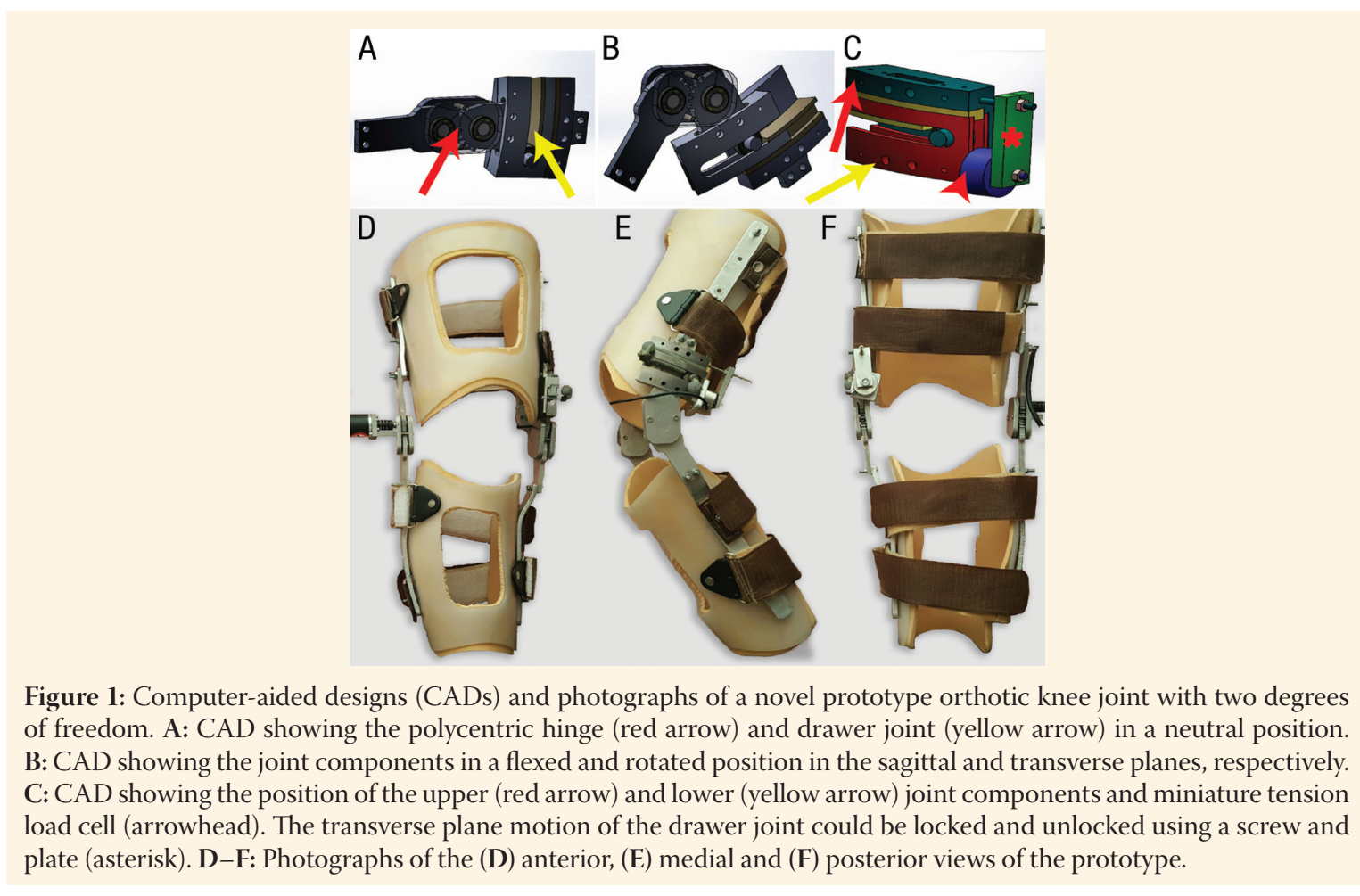


Table 1: Manufacturing characteristics of a novel prototype orthotic knee joint with two degrees of freedom

$\begin{array}{lr}\text { Characteristic } & \text { Measurem } \\ \text { Aluminium polycentric hinge } & 100 \\ \text { Weight in g } & 50 \\ \text { Height in mm } & 33 \\ \text { Width in mm } & 18 \\ \text { Thickness in mm } & 140 \\ \text { Range of motion in degrees } & \\ \text { Stainless steel drawer joint } & 300 \\ \text { Weight in g } & 47 \\ \text { Height in mm } & 60 \\ \text { Width in mm } & 15 \\ \text { Thickness in mm } & 20 \\ \text { Range of motion in degrees } & \\ \text { Aluminium sidebars } & 5 \\ \text { Thickness in mm } & 20 \\ \text { Width in mm } & \end{array}$

to the seat when the subject was in a sitting position. The feet were kept parallel to one another on the ground while the arms were placed against the chest. A miniature tension load cell (UMMA ${ }^{\circledR} 100 \mathrm{~kg}$-force model, DACELL Co. Ltd., Nami-myeon, Cheongwon-gun, South Korea) was used to measure the interactive shearing force between the limb and orthosis in the shell area during knee joint motions. The load cell was embedded between the posterior aspect of the orthotic joint in the medial side and the detachable aluminium plate [Figure $1 \mathrm{C}$ ]. In order to measure the angle of knee flexion at the moment of lowest and highest interactive shearing force between the limb and orthosis, an incremental rotary encoder (E30S series, AUTONICS
Co. Ltd., Busan, South Korea) allowing 1,000 pulses/ revolution was installed co-axially at the centre of the orthotic joint on the lateral side. After three practice sit-to-stand trials, the mean values were calculated for the final analysis.

The output signal of the miniature tension load cell was filtered through a low pass filter and amplified 1,000 times using a DN-AM100 ${ }^{\circledR}$ dynamic load cell amplifier (DACELL Co. Ltd.). The amplified voltage was then digitised using a 3.3-V 84- $\mathrm{MHz}$ Arduino $\mathrm{Du}$ $\mathrm{e}^{\circledR}$ ARM core data acquisition board (Arduino, Turin, Italy). The microcontroller in the data acquisition board was programmed with custom software and the recorded data were uploaded to a computer from a secure digital card. The results were input into an Excel spreadsheet, Version 2013 (Microsoft Corp., Redmond, Washington, USA) and presented in the form of a line chart.

All procedures and components involved in the design, implementation and testing of the prototype were approved by the Ethics Committee of the Iran University of Medical Sciences (\#92-11-50-3209). Voluntary informed consent was provided by the subject prior to the testing of the prototype.

\section{Results}

When the transverse plane of the orthotic knee joint was locked (i.e. providing only one DOF), the orthotic joint only partially mimicked the path of the anatomic knee during the sit-to-stand task, allowing only flexion and extension movement. Furthermore, the miniature tension load cell mounted behind the joint detected a mean shearing force load of 45 Newtons $(\mathrm{N})$ between the limb and orthosis in the shell area when the subject sat down and flexed his knee to approximately 90 degrees. The amount of force increased as the flexion angle exceeded 40 degrees, with the maximum amount of force occurring in the final phase of the sitting move-

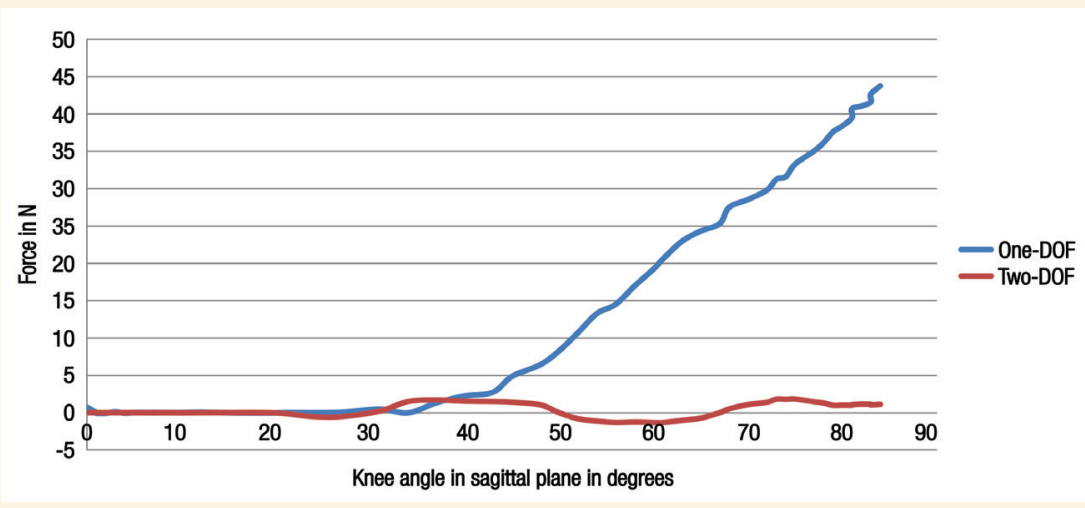

Figure 2: Line graph showing the interactive shearing force load between the limb and orthosis in the shell area during a sit-to-stand task using a novel prototype orthotic knee joint with two degrees of freedom (DOF) compared to one DOF alone.

$N=$ Newtons; $D O F=$ degrees of freedom. 

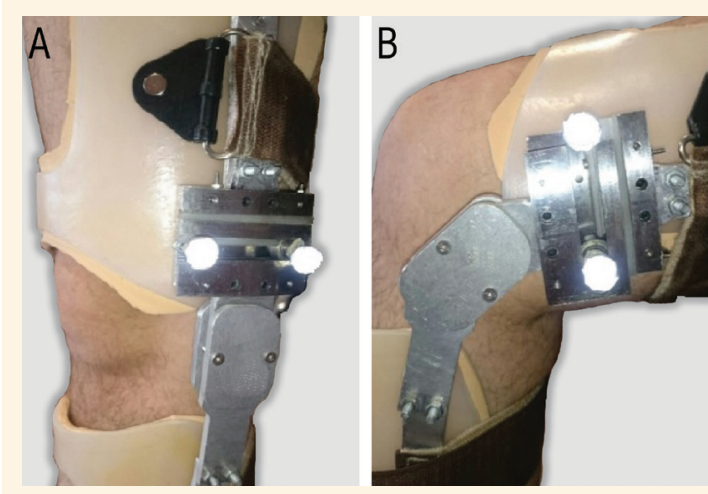

Figure 3: Photographs showing the displacement of the upper and lower components of the drawer joint of a novel prototype orthotic knee joint with two degrees of freedom. During a sit-to-stand test, these two components were displaced by $15 \mathrm{~mm}$ when the subjects flexed his knees from (A) full extension to (B) approximately 90 degrees, representing movement in the transverse plane.

ment, when the knees were flexed at approximately 90 degrees. This interactive shearing force was transmitted through the sidebars into the orthotic joint.

However, when the task was repeated with the transverse plane unlocked (i.e. providing two DOF), the orthotic joint was able to more closely mimic natural knee joint movements. In addition, the miniature tension load cell detected almost no load when the subject sat down and flexed his knee to approximately 90 degrees [Figure 2]. The subject also declared that he was more comfortable while seated when the transverse plane was unlocked. The maximum displacement of the rotary part of the orthotic joint in the transverse plane (i.e. the drawer joint) between the two sliding components was $15 \mathrm{~mm}$. This occurred just after the subject had begun to sit down from a standing position [Figure 3].

\section{Discussion}

Patients often report discomfort, poor fit and skin irritation as reasons for poor compliance with or discontinuation of the use of knee braces. ${ }^{11,12}$ Furthermore, previous research indicates that KOA patients wear their braces for less than four hours a day. ${ }^{13,14}$ There is therefore a need to redesign knee orthotic devices in order to increase wear time, more closely mimic natural movement and reduce patient discomfort. ${ }^{12}$ Accordingly, a novel prototype orthotic knee joint with two DOF in both the sagittal and transverse planes was designed and tested on a subject with medial KOA.

When the transverse plane of the two-DOF prototype was locked into a one-DOF setting, the mounted load cell behind the joint detected a mean shearing force load of $45 \mathrm{~N}$. This could be due to mismatch between the movement of the orthotic and anatomic joints as the orthosis attempted to force the knee to follow a simplified movement pattern, thereby preventing natural rotary motion. As a result, unwanted constraint force (i.e. interactive shear force) was generated between the orthosis and the limb in contact areas. As the flexion angle exceeded 40 degrees, the amount of force increased. The maximum amount of force was recorded in the very last phase of movement into a seated position, when the subject flexed his knees to approximately 90 degrees. This is understandable considering that the limb volume increases as the knee joint moves into deep flexion. ${ }^{15}$ In other words, as the motion of the orthotic joint does not accurately reflect natural knee kinematics, the tightly fitting interface magnifies the pistoning constraint, leading to a high load.

However, when the transverse plane of the prototype was unlocked to allow two DOF, there were fewer limitations in the path of the anatomic knee joint. As such, the subject was able to both flex and rotate his knee, allowing for a much freer range of motion. The internal and external rotation decreased the extra shearing force between the limb and orthosis, resulting in increased comfort for the wearer when sitting and standing, which are movements which require deep flexion and among the most routinely practiced activities in daily living. ${ }^{16}$

\section{Conclusion}

A novel prototype orthotic knee joint with two DOF was designed to more accurately reflect natural knee movements by allowing motion in both the sagittal and transverse planes. When compared with the one-DOF setting, the two-DOF mechanism allowed the subject to move his knee more freely and complete the range of motion with a lower constraint force when sitting and standing. Such devices are recommended to mitigate the inconvenience and discomfort associated with traditional one-DOF knee braces, thereby improving the quality of life of patients with KOA.

\section{CONFLICT OF INTEREST}

The authors declare no conflicts of interest.

\section{FUNDING}

No funding was received for this research.

\section{References}

1. Gaasbeek RD, Groen BE, Hampsink B, van Heerwaarden RJ, Duysens J. Valgus bracing in patients with medial compartment osteoarthritis of the knee: A gait analysis study of a new brace. Gait Posture 2007; 26:3-10. https://doi.org/10.1016/j.gaitpost. 2006.07.007. 
2. Komistek RD, Dennis DA, Northcut EJ, Wood A, Parker AW, Traina SM. An in vivo analysis of the effectiveness of the osteoarthritic knee brace during heel-strike of gait. J Arthroplasty 1999; 14:738-42. https://doi.org/10.1016/S0883-5403(99) 90230-9.

3. Richards JD, Sanchez-Ballester J, Jones RK, Darke N, Livingstone BN. A comparison of knee braces during walking for the treatment of osteoarthritis of the medial compartment of the knee. J Bone Joint Surg Br 2005; 87:937-9. https://doi.org/10.1302/0301620X.87B7.16005.

4. Branch TP, Hunter RE. Functional analysis of anterior cruciate ligament braces. Clin Sports Med 1990; 9:771-97.

5. Cawley PW, France EP, Paulos LE. Comparison of rehabilitative knee braces: A biomechanical investigation. Am J Sports Med 1989; 17:141-6. https://doi.org/10.1177/036354658901700201.

6. Lewis JL, Lew WD, Patrnchak CM, Shybut GT. A new concept in orthotics joint design: The Northwestern University Knee Orthosis System. Orthot Prosthet 1983; 37:15-23.

7. Choi B, Lee Y, Kim J, Lee M, Lee J, Roh SG, et al. A self-aligning knee joint for walking assistance devices. Conf Proc IEEE Eng Med Biol Soc 2016; 2016:2222-7. https://doi.org/10.1109/ EMBC.2016.7591171.

8. Regalbuto MA, RovickJS, Walker PS. The forces in a knee brace as a function of hinge design and placement. Am J Sports Med 1989; 17:535-43. https://doi.org/10.1177/036354658901700415.

9. Walker PS, Rovick JS, Robertson DD. The effects of knee brace hinge design and placement on joint mechanics. J Biomech 1988; 21:965-74. https://doi.org/10.1016/0021-9290(88)90135-2
10. Kellgren JH, Lawrence JS. Radiological assessment of osteoarthrosis. Ann Rheum Dis 1957; 16:494-502. https://doi.org/ 10.1136/ard.16.4.494

11. Squyer E, Stamper DL, Hamilton DT, Sabin JA, Leopold SS. Unloader knee braces for osteoarthritis: Do patients actually wear them? Clin Orthop Relat Res 2013; 471:1982-91. https://doi.org/10.1007/s11999-013-2814-0.

12. Arazpour M, Hutchins SW, Bani MA, Curran S, Aksenov A. The influence of a bespoke unloader knee brace on gait in medial compartment osteoarthritis: A pilot study. Prosthet Orthot Int 2014; 38:379-86. https://doi.org/10.1177/0309364613504780.

13. Jones RK, Nester CJ, Richards JD, Kim WY, Johnson DS, Jari S, et al. A comparison of the biomechanical effects of valgus knee braces and lateral wedged insoles in patients with knee osteoarthritis. Gait Posture 2013; 37:368-72. https://doi.org/10.1016/j. gaitpost.2012.08.002.

14. Zhang W, Moskowitz RW, Nuki G, Abramson S, Altman RD, Arden N, et al. OARSI recommendations for the management of hip and knee osteoarthritis: Part II - OARSI evidence-based, expert consensus guidelines. Osteoarthritis Cartilage 2008; 16:137-62. https://doi.org/10.1016/j.joca.2007.12.013.

15. Neumann DA. Kinesiology of the Musculoskeletal System: Foundations for rehabilitation, 2nd ed. St. Louis, Missouri, USA: Mosby, 2009. Pp. 463-681.

16. Frykberg GE, Häger CK. Movement analysis of sit-to-stand: Research informing clinical practice. Phys Ther Rev 2015; 20:156-67. https://doi.org/10.1179/1743288X15Y.0000000005. 